\title{
Fractography and Tensile Properties of AA6061 Aluminium Alloy/ Rice Husk Ash Silicon Nanocomposite
}

\author{
N. E. Udoye $\mathbb{D}^{1}{ }^{1}$ O. S. I. Fayomi, ${ }^{1,2}$ and A. O. Inegbenebor ${ }^{1}$ \\ ${ }^{1}$ Department of Mechanical Engineering, College of Engineering, Covenant University, Ota, Ogun State, Nigeria \\ ${ }^{2}$ Department of Chemical, Metallurgical and Materials Engineering, Tshwane University of Technology, Private Bag X680, \\ Pretoria 0001, South Africa \\ Correspondence should be addressed to N. E. Udoye; nduka.udoye@covenantuniversity.edu.ng
}

Received 22 May 2020; Revised 17 July 2020; Accepted 12 August 2020; Published 28 August 2020

Academic Editor: Rotimi Sadiku

Copyright ( $) 2020$ N. E. Udoye et al. This is an open access article distributed under the Creative Commons Attribution License, which permits unrestricted use, distribution, and reproduction in any medium, provided the original work is properly cited.

\begin{abstract}
The unstoppable quest for low-cost reinforcing agent gingered the enthusiasm towards developing and utilising the agro-based waste product as reinforcement since they are promptly accessible, sustainable, and inexpensive to purchase. In this study, AA6061/rice husk ash matrix composites were produced through metallurgical stir casting techniques. Different weight percentages of reinforcement in the range of $2 \%, 4 \%, 6 \%$, and $8 \%$ were used to fabricate the composites. The reinforced composites were characterized by SEM/EDS for microstructural study. The mechanical behaviour was examined for all the produced samples. SEM/EDS analysis revealed the presence of silica, a major constituent of rice husk ash in the produced composites. The results of the mechanical behaviour show that upgrading the weight percentage of reinforcing agent increases the mechanical properties. AA6061/8\% rice hush ash generated a consistent rise with filler concentration in comparison with the aluminium alloy in all operating functions.
\end{abstract}

\section{Introduction}

The high cost of ceramic material prompts the use of ecofriendly inexpensive agro-based waste reinforcing materials on aluminium-based alloys for industrial application $[1,2]$. The utilization of modern technologies for reducing severe failures in major engineering component is necessary for metal construction industries as a result of its innovative qualities, and studies have revealed that aluminium alloy is the cheapest and global valuable materials $[3,4]$. Aluminium alloy is a class of aluminium with low density, light weight, ultimate tensile strength, and hardness $[5,6]$. The high demand for aluminium applied in the different application is unquantifiable to the implementation of other metals. Moreover, aluminium is utilized in numerous fields, starting from building construction to kitchen wares. Aluminium and its alloys are applied in numerous factories as a result of their encompassing properties such as higher strength-toweight ratios, decent corrosion resistance, and exceptional workability [7]. The production of aluminium is invariably broad as it embraces different stages of the metallurgical path. The quest to create cheaper materials, particularly metal matrix composites (MMCs) with enriched structures, has occupied the attention of many researchers $[8,9]$. Pure aluminium cannot be used for structural applications except when other elements are included in the substance to obtain sufficient strength for the production of structural members [10]. MMCs are utilized immensely in industrial processes involving light weight with stiffness, superspecific strength, ductility, and resistance due to heat [11]. Fly ash, fibres, whiskers, and particles are few examples of agro-based waste particulate used recently for reinforcement $[12,13]$. Numerous researchers desire to use cheaper materials to reinforce aluminium alloy, particularly metal matrix composite with superior properties [14]. However, AA6061 alloy has rough particles and enormous needle/plate-like eutectic silicon, which resulted in low mechanical behaviour. AA6061 alloys are a cluster of Al-Si-Mg and their rises in strength are by the processing of $\mathrm{Mg}_{2} \mathrm{Si}$ in the aluminium alloy [10]. The enthusiasm in the improvement of metal 
matrix composites (MMCs) is anchored on its mechanical applications for light materials with a unique quality, malleability, and thermal resistance [15]. The desire to produce inexpensive smart composite necessitates numerous inventions in the technological world. Among the several reinforcements used like silicon carbide and aluminium oxide, rice husk ash is the lowest reinforcement attainable in huge quantity as an agro-based waste [16, 17]. Rice husk ash (RHA) was selected because of inherent composition such as silicon embedded in the material. Silicon has high melting and boiling points of $1414^{\circ} \mathrm{C}$ and $3265^{\circ} \mathrm{C}$, which contributed to reducing the melting temperature of the produced composites.

In the current study, the use of AA6061/RHA composites to boost the structural properties of the material was determined. Senapati et al. explore the use of agro-based discarded RHA and fly ash to strengthen the aluminium alloy used in the manufacturing industry. The author deduced that the addition of fly ash and rice husk particulates in the aluminium alloy advances the matrix hardness and the wear properties of the composite [18]. Prasad and Krishna examined the mechanical features of AA356.2/RHA composites. The authors observed more anticipated surface morphology and mechanical characteristics than the as-received sample. The result depicts that the presence of RHA particles leads to the improvement in hardness and strength of the developed composite [2]. Subrahmanyam et al. carried out inoculation of aluminium alloy using agricultural waste rice husk ash. The authors observed that the mechanical properties of MMCs performed better with the inclusion of RHA in aluminium alloy. The microstructure with $8 \%$ RHA particles has exceptional mechanical properties and uniformly distributed particulates [19].

According to Haque et al., "the production of inexpensive metal matrix composites strengthened with ecofriendly material has contributed to revolutions in the field of engineering to limit environmental pollution". The authors fabricated and characterized the reinforcement of AA356.2 alloy with RHA particulates. The microstructure study reveals homogeneous dispersal of RHA particulates in the produced composites. Furthermore, it shows that the toughness measured by impact test increases as RHA content increases. It was affirmed that AA356.2/RHA composites could be utilized where light-weight materials are needed with better stiffness and strength [20].

Valyakala et al. studied the source of the destruction of a forced draft fan based on a study carried out in the petrochemical industry. The major factor affecting the failure rate of forced draft fan in a petrochemical industry was vibration, and vibration in turn caused bearing failure. The causes of failure of the fan blade are divided into four main parts: machine, material, equipment, and labour. The authors affirmed that suspended particles in the air instigate erosion on the blades. Therefore, the authors concluded that forced draft fan damage was caused by bearing damage, and it can be evaded by eliminating disruption in the impeller and misalignment of base and fastener failure [21]. Kushwaha studied failure analysis and technique of averting fracture in the generator's fan blade. The authors concluded that the blade crack was due to fatigue situations in resonance state and the growth of existing small feasible cracks [22].

The research complications envisaged are the deformations of machine parts due to environmental generated failure altering the grain borderline. The study provides agro-based waste to boost aluminium alloy in the manufacturing industries. The study aimed to determine the fractography and tensile properties of AA6061 aluminium alloy/rice husk ash silicon nanocomposite to curb the constant failure of equipment in the industry.

\section{Materials and Methods}

2.1. Matrix Material. The matrix material used in this work is aluminium 6061. Aluminium 6061 is an alloy of aluminium whose main alloying elements are magnesium and silicon. This material is made use of in this work because of the mechanical properties it exhibits, such as strength and good welding ability. In the present study, the chemical composition of the matrix is shown in Table 1.

2.2. Reinforcement Materials. In this study, the reinforcement material is rice husk ash. It is made from rice mill plant in Abakaliki, Ebonyi State. The RHA is cleaned with water to exclude the dust and dehydrated at room temperature for one day. Washed rice husk is then heated to $200^{\circ} \mathrm{C}$ for one hour to get rid of the moisture. It is then heated to $600^{\circ} \mathrm{C}$ for $12 \mathrm{~h}$ to eradicate the carbon content. The chemical element of RHA is shown in Table 2. Figure 1 shows the flowchart for the processing of rice husk ash.

2.3. Mechanical Properties. Mechanical properties for prepared composites of varying reinforcements were assessed in hardness and tensile properties. The Brinell hardness was measured at a load of $100 \mathrm{~g}$ for 15 seconds. The universal testing machine (UTM) SM1000 was used in this work for testing the material tensile strengths.

2.4. Preparation of Composite Samples. The production of AA6061/rice husk ash was done effectively by stir casting method. The study was carried out at different percentage compositions of reinforcement. Firstly, AA6061 is poured into the red heated electrical furnace and the temperature is raised to $750^{\circ} \mathrm{C}$ until total melting. Slag is extracted to generate good quality of the melt. The obtained RHA is preheated to $600^{\circ} \mathrm{C}$ in a detached oven and maintained for 20 minutes to eradicate moisture content. The picture of the stir cast arrangement is shown in Figure 2. The mechanical stirrer is dipped into the melt and slowly stirred to create a vortex. Then the preheated rice husk ash is poured to the melt at a temperature of $720^{\circ} \mathrm{C}$.

Concurrently, the stirring preparation is taken and transferred at a temperature of $650^{\circ} \mathrm{C}$ into the preheated moulds of $250 \mathrm{~mm} \times 25 \mathrm{~mm}$ size cylindrical hole instantly. Precaution is ensured for the thorough conversion of the molten metal to solid. Figure 3 shows the developed composite material before the tensile test. 
TABle 1: Chemical composition of AA6061 (wt. \%).

\begin{tabular}{lcccccccc}
\hline Element & $\mathrm{Al}$ & $\mathrm{Mg}$ & $\mathrm{Si}$ & $\mathrm{Fe}$ & $\mathrm{Cu}$ & $\mathrm{Zn}$ & $\mathrm{Mn}$ & $\mathrm{O}$ \\
\hline Composition & 85.0 & 3.3 & 2.25 & 2.13 & 1.5 & 0.25 & 0.12 & 5.0
\end{tabular}

TABLE 2: Chemical element of RHA reinforcing filler (wt. \%).

\begin{tabular}{lccccccc}
\hline Constituents & $\mathrm{SiO}_{2}$ & $\mathrm{Al}_{2} \mathrm{O}_{3}$ & $\mathrm{Fe}_{2} \mathrm{O}_{3}$ & $\mathrm{CaO}$ & $\mathrm{MgO}$ & $\mathrm{Na}_{2} \mathrm{O}$ & $\mathrm{K}_{2} \mathrm{O}$ \\
\hline (wt. \%) & 81.05 & 12.1 & 0.98 & 0.58 & 1.98 & 0.06 & 3.25 \\
\hline
\end{tabular}

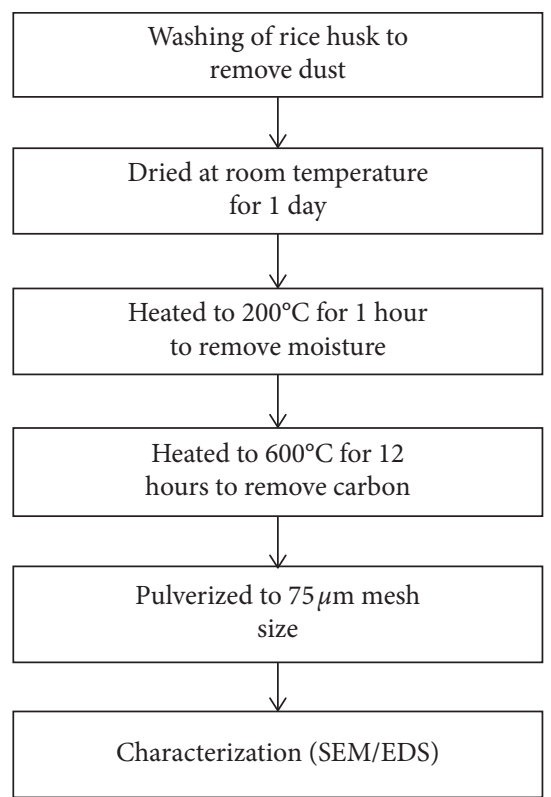

FIgURE 1: The flowchart for the processing of RHA.

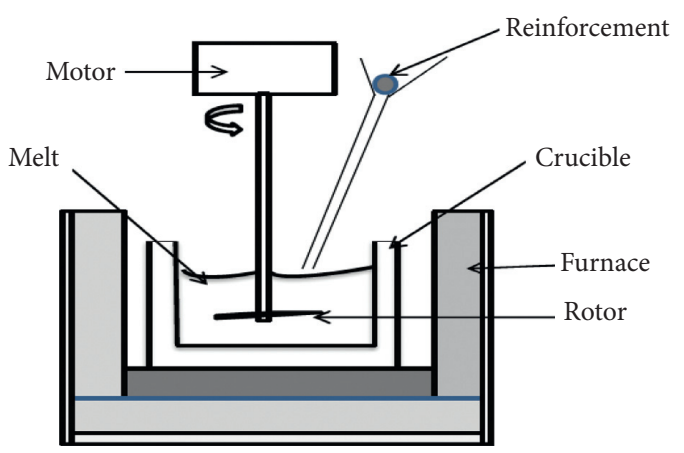

FIgURE 2: Stir casting technique for the fabrication MMCs.

\section{Equipment}

3.1. Hardness Testing. The Brinell hardness experiment was done using a $10 \mathrm{~mm}$ steel ball indenter TQ SM1000 universal testing machine, the tiny circular specimens were placed in a cavity connected to the axis as a steel ball indenter, and then the steel ball using a lever having hydraulic energy is pushed into the sample for $10 \mathrm{~s}$ observation and continued reading the applied force on the digital readout screen. The diameter of the indentation on the samples was determined in a granule
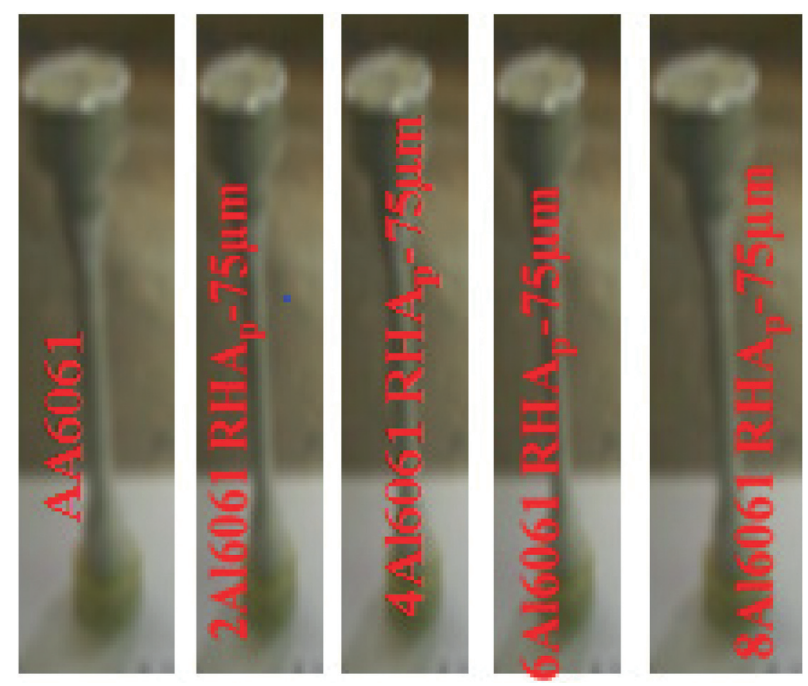

Figure 3: Developed composite material before the tensile test.

consisting of a magnifying glass having a weighing scale. The Brinell hardness value was based on the Brinell scale formula as follows:

$$
\mathrm{HBS}=\frac{2 F}{\pi D\left(D-\sqrt{D^{2}-d^{2}}\right)}
$$

where $\mathrm{HBS}=\mathrm{H}$ (hardness), B (Brinell), $\mathrm{S}$ (steel), $F=$ applied force, $D=$ diameter of indenter, and $d$ =diameter of indentation [23].

3.2. Universal Material Testing Machine. The SM1000 Universal Test Machine Cap $100 \mathrm{kN}$ (10 ton) is used to determine the tensile strength of the developed composites. It is a universal test machine (UTM) commonly known as the universal tester. It is very versatile as it was used to perform the tensile strength tests. This is a multifunctional tensile and hardness testing machine.

3.3. Scanning Electron Microscope (SEM). The scanning electron microscope (SEM) was used to perform the microstructural examinations and phase analysis for each reinforced sample. The microscope is reinforced by an energy dispersion spectrometer (EDS) to determine the quantified composite identity of the elements present in the working samples. For unified elementary research, the TESCAN scanning electron instrument enables high vacuum resolution separation.

\section{Results and Discussion}

4.1. Morphology Study of AA6061/Rice Husk Ash Reinforcement. Figure 4 shows the SEM/EDS of as-received sample depicting the significant presence of aluminium from the EDS analysis. Figure 5 shows the microstructure of the developed composite prepared by stir casting methods. A homogeneous dispersal of RHA is noticed visibly in Figure 5(b) without cavities and gaps. Figure 6(b) shows the presence of eutectic silicon $\alpha$-Al phase precipitation and uneven 


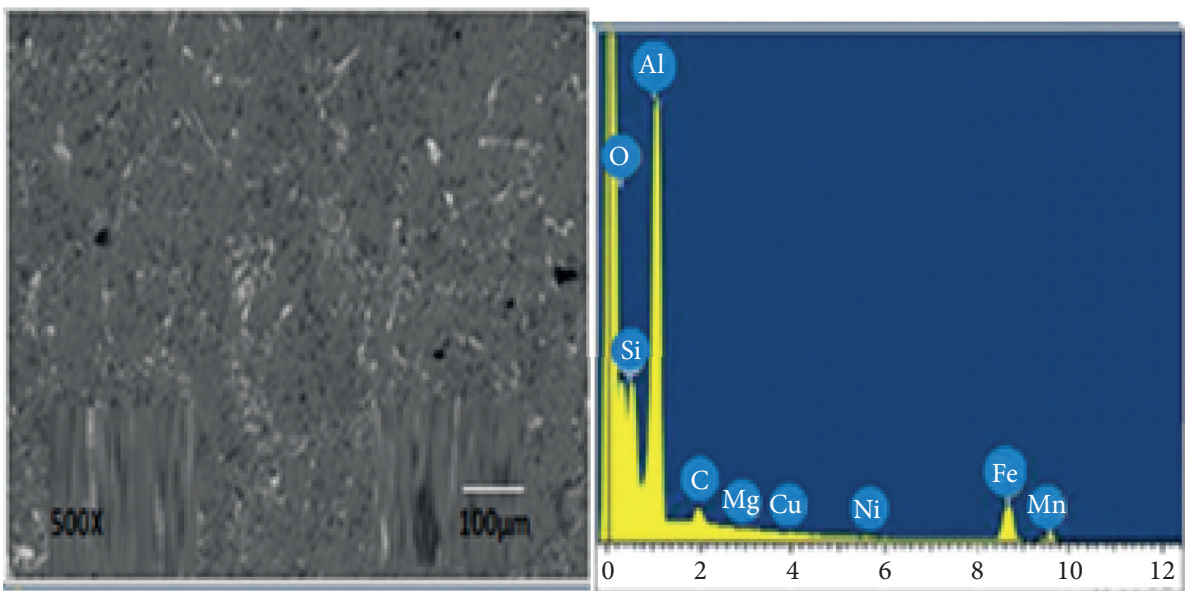

FIGURE 4: SEM/EDS spectra for as-received AA6061.
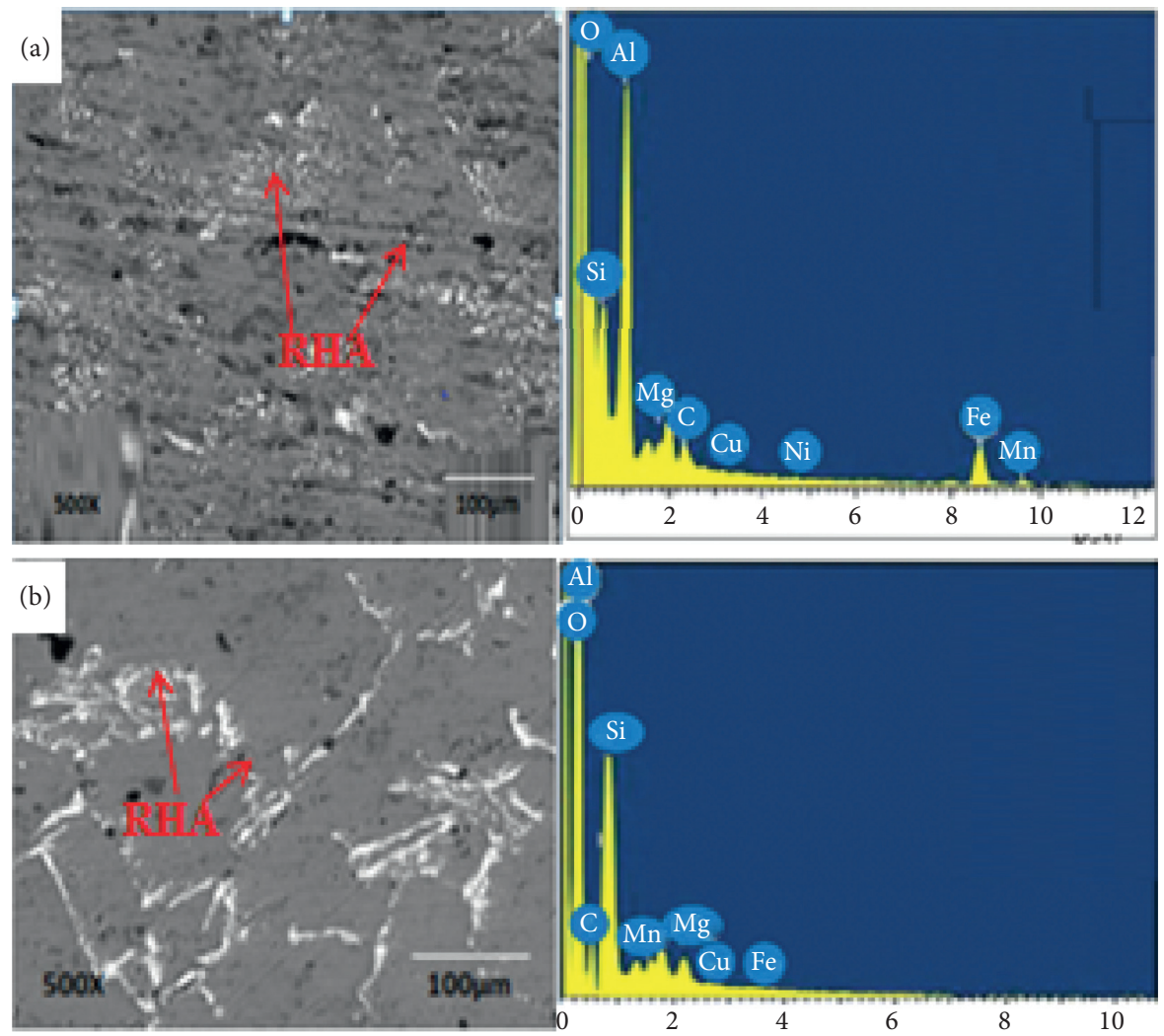

Figure 5: SEM micrograph showing (a) AA6061/2\% RHA at $75 \mu \mathrm{m}$ and (b) AA6061/4\% RHA at $75 \mu \mathrm{m}$.

distribution of particulate grain refiners. More developed and uniform dispersal of particulates is observed for the sample AA6061/8\% RHA at $75 \mu \mathrm{m}$. It was noticed that a needle-like particle with well-structured crystal due to the improved arrangement of the reinforcement existed with the elemental composition of all basic collections seen at the EDS. It is interesting to note that the percentage of reinforcements plays a vital role in the stable modification of crystal. In this work, studies by Saravanan and Kumar stated that prospective ceramics particles have an intensity to cause consistent growth due to the nucleation system as seen in Figure 6(b) [24]. Siddharth and Rao stated that the addition of reinforcing agent led to the building of the silica-rich layer at the matrix margin [25].

4.2. Fractured Surface Analysis of AA6061/RHA Composite. The fractured surfaces of the tensile specimens were examined using a scanning electron microscope (SEM), which gives the fracture propagation of the tensile specimens, and Figure 7 shows the fractured SEM image of the starting material. It revealed a flat fracture surface consisting of small fracture facets and tear ridges in the microstructure 

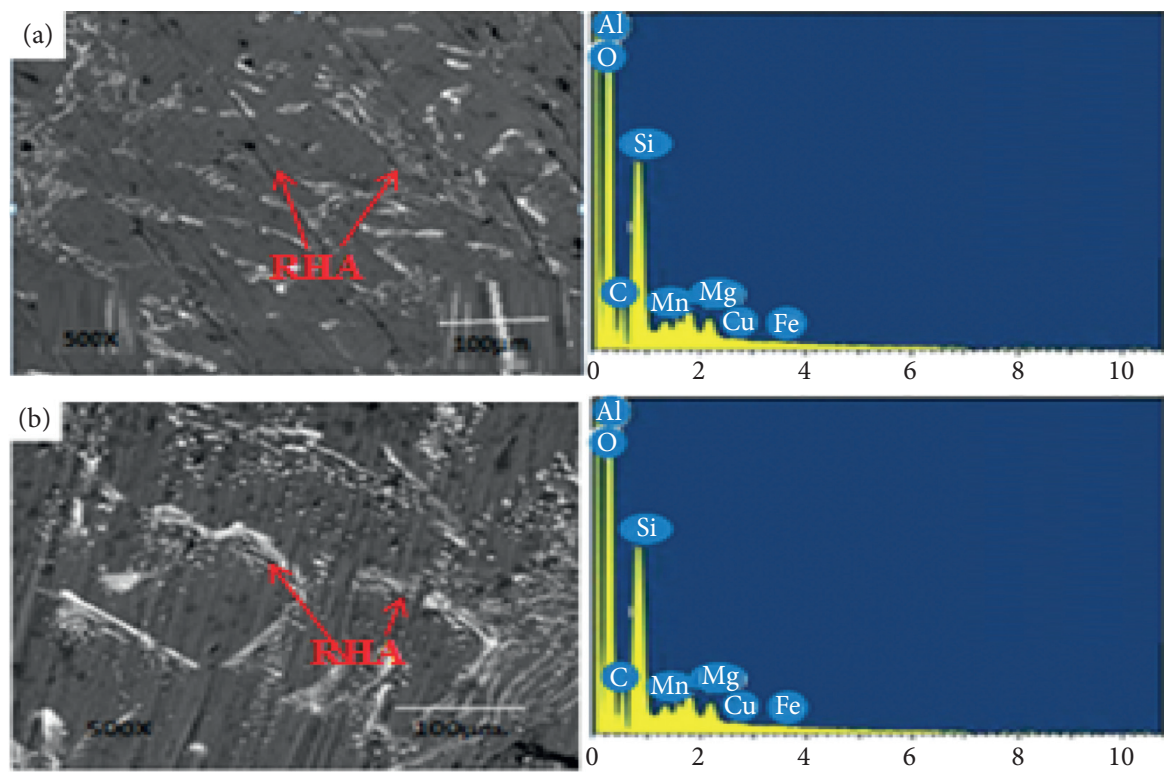

Figure 6: SEM micrograph showing (a) AA6061/6\% RHA at $75 \mu \mathrm{m}$ and (b) AA6061/8\% RHA at $75 \mu \mathrm{m}$.

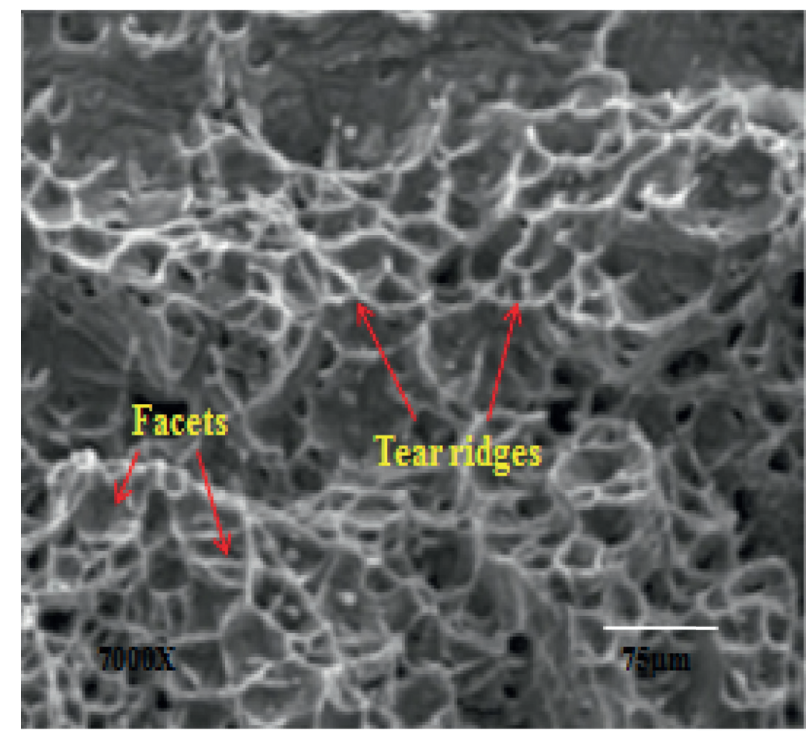

Figure 7: Fractography images of the starting material.

images of the starting material indicating that it is a ductile fracture. Figure 8(a) illustrates the detailed fracture surface morphologies of AA6061/2\% RHA composites. The fractured SEM images show a flat fracture surface involving wear track and tear ridges. Maleque et al. stated that fracture occurs in composite material by crack initiation which followed immediately at the boundary between aluminium alloy and reinforcement, and the ductile properties are characterized by the wear track and tear ridges observed on the fractured surface [26].

Figure 8(b) shows the fractography of AA6061/4\% RHA composites. It can be observed to have irregular tear ridges and less ductile failure due to more voids and fewer depths of dimple before reinforcements. Figure $8(\mathrm{c})$ shows the fractography analysis of AA6061/6\% RHA composites. It revealed a noticeable dimple effect of the fracture surface, which specifies the ductility of the material. Figure $8(d)$ shows that AA6061/8\% RHA has a higher tensile strength than the as-received sample because of the ductile nature of the material. However, AA6061/8\% RHA reveals a noticeable fracture surface after tensile tests in macroscopic images and equal deep dimples spread over the fracture surface. Dimples enclose the greater area with considerable dimple depth and intermetallic segregation which is due to the reinforced agent present in the matrix [27, 28].

\subsection{Evaluation of Mechanical Behaviour}

4.3.1. Microhardness Analysis of RHA Reinforced AA6061. 

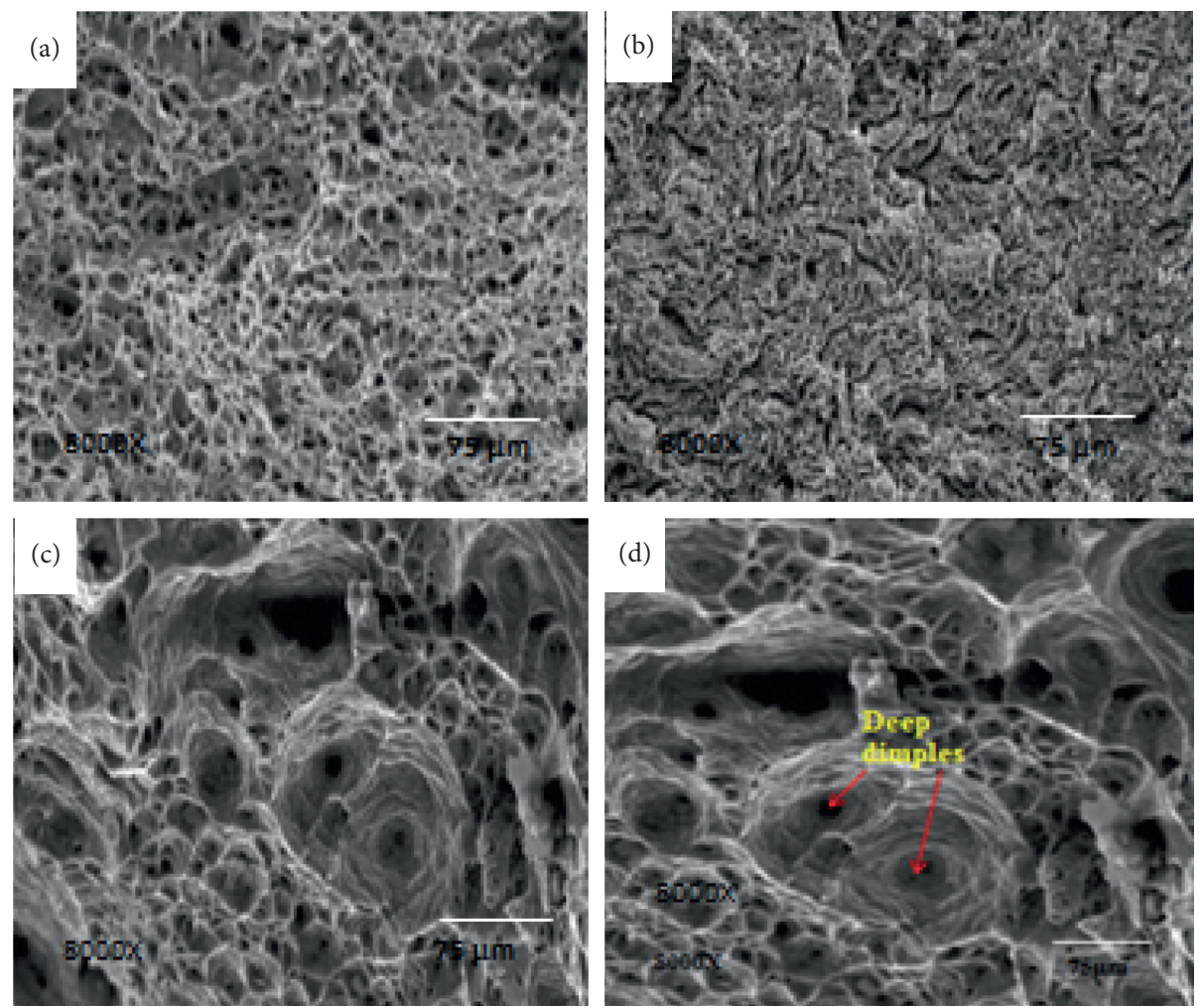

Figure 8: SEM after fracture of (a) AA6061/2\% RHA at $75 \mu \mathrm{m}$, (b) AA6061/4\% RHA at $75 \mu \mathrm{m}$, (c) AA6061/6\% RHA at 75 $\mu \mathrm{m}$, and (d) AA6061/8\% RHA at $75 \mu \mathrm{m}$.

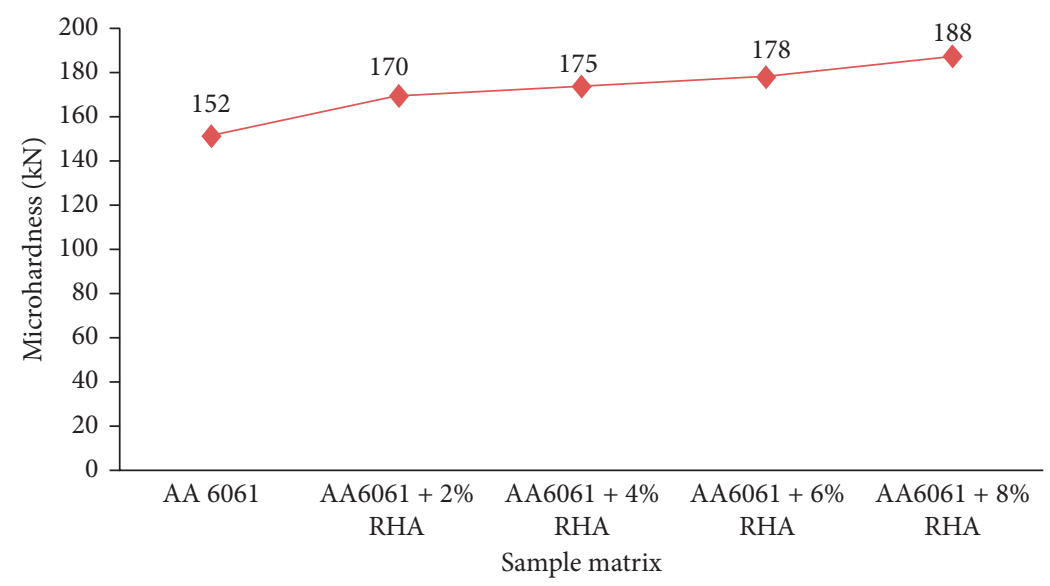

Figure 9: Effect of RHA content on microhardness.

Figure 9 represents the microhardness plot and variable pattern of the reinforced alloys for AA6061/RHA alloy in $75 \mu \mathrm{m}$ grain sizes. From the obtained data, the fabricated alloys increased linearly in hardness from $152 \mathrm{BHN}$ to approximately $188 \mathrm{BHN}$ at a percentage increment of $23.7 \%$. For critical comparison of the reinforced matrixes, AA6061/ $8 \%$ RHA at $75 \mu \mathrm{m}$ amidst all others gave a better hardness. Apasi et al. stated that the result of the hardness increase of the alloy composite is seen to be similar to other experiments conducted by the author [29].
4.3.2. Ultimate Tensile Strength for RHA Reinforced AA6061. Figure 10 shows the UTS trend and variable design of reinforced alloys for AA6061/RHA alloy in $75 \mu \mathrm{m}$ grain sizes. The UTS of the reinforced aluminium MMCs increased significantly from $6000 \mathrm{kPa}$ starting aluminium alloy to approximately $6339 \mathrm{kPa}$ for the developed alloy at a performance influence of $5.65 \%$. For an accurate evaluation of the reinforced matrixes, AA6061/8\% RHA at $75 \mu \mathrm{m}$ amidst all others gave a superior ultimate tensile strength. Gupta and Takhi stated that the higher the percentage of 


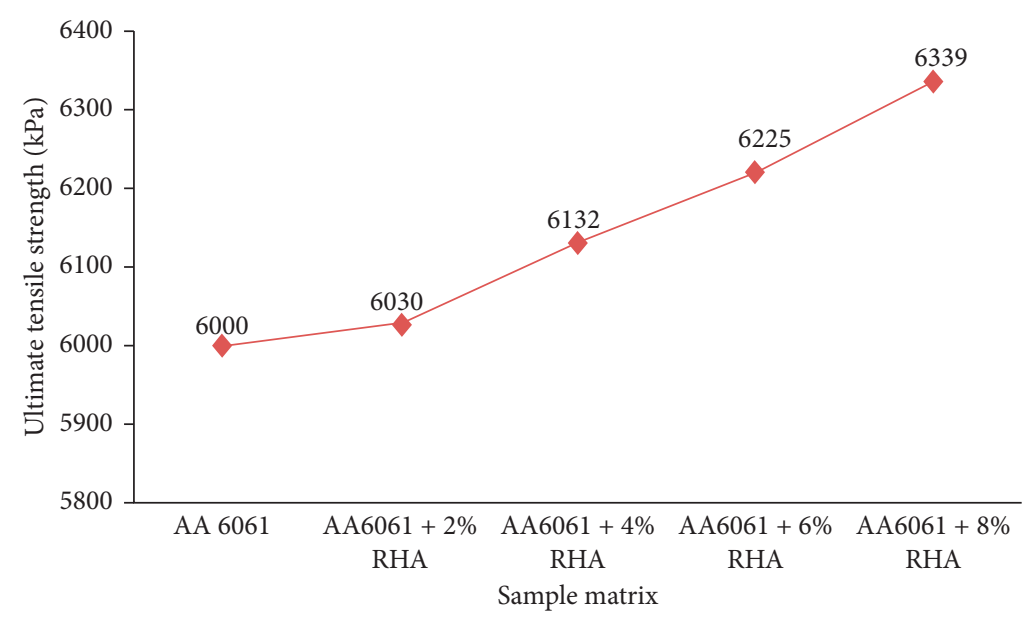

Figure 10: Effect of RHA particles on tensile strength.

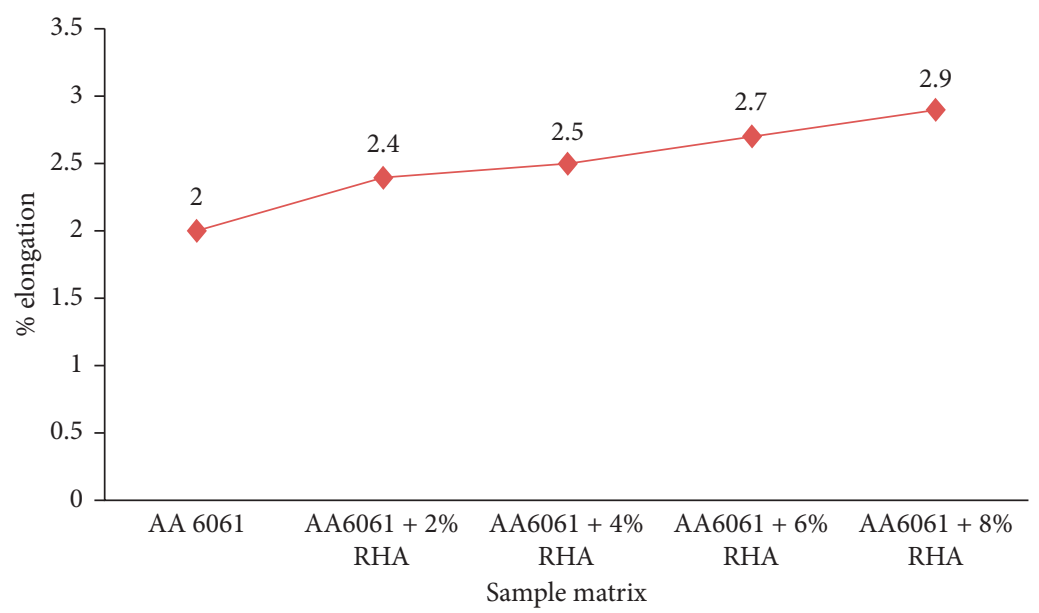

Figure 11: Effect of RHA particles on percentage elongation.

RHA added to the matrix, the higher its tensile strength, thereby causing a boost in the mechanical properties [30].

\subsubsection{Elongation Result for Reinforced Aluminium Matrix.} Figure 11 shows the percentage elongation analysis and variable influence of the reinforced alloys for AA6061/RHA alloy in $75 \mu \mathrm{m}$ grain sizes. From the compared process parameter, AA6061 + 8\% RHA at $75 \mu \mathrm{m}$ among the others gave a better superior percentage elongation than the asreceived sample. It is noticed that the elongation of composite reduced with the reduction in the percentage of the reinforcement [7].

\section{Conclusion}

The following conclusions were made:

Agro-based waste rice husk ash particulate can be utilized for the production of MMCs for industrial applications.

AA6061 was successfully reinforced with rice husk through a liquid metallurgy stir casting route.
AA6061/8\% RHA gives the maximum tensile value of $6339 \mathrm{kPa}$ in comparison with the $6000 \mathrm{kPa}$ for the asreceived sample in all operating conditions.

The developed metal matrix agro-refiner alloy greatly improved the hardness from $152 \mathrm{BHN}$ to $188 \mathrm{BHN}$ at a performance influence of $23.7 \%$.

\section{Data Availability}

The data used to support the findings of this study are included within the article.

\section{Conflicts of Interest}

The authors declare that there are no conflicts of interest.

\section{Acknowledgments}

The authors acknowledge Covenant University for the financial support offered for the publication of this research. 


\section{References}

[1] K. K. Alaneme, T. M. Adewale, and P. A. Olubambi, "Corrosion and wear behaviour of Al-Mg-Si alloy matrix hybrid composites reinforced with rice husk ash and silicon carbide," Journal of Materials Research and Technology, vol. 3, no. 1, pp. 9-16, 2014.

[2] D. S. Prasad and A. R. Krishna, "Fabrication and characterization of AA356.2-Rice husk ash composite using stir casting technique," International Journal of Engineering Science and Technology, vol. 2, no. 12, pp. 7603-7608, 2010.

[3] G. Wang, L. Zhu, H. Liu, and W. Li, "Zinc-graphite composite coating for anti-fouling application," Materials Letters, vol. 65, no. 19-20, pp. 3095-3097, 2011.

[4] Z. F. Lin, X. B. Li, and L. K. Xu, "Electrodeposition and corrosion behavior of zinc-nickel films obtained from acid solutions: effects of TEOS as additive," International Journal Electrochemical Science, vol. 7, pp. 12507-12517, 2012.

[5] N. E. Udoye, O. S. I. Fayomi, and A. O. Inegbenebor, "Assessment of wear resistance of aluminium alloy in manufacturing industry-a review," Procedia Manufacturing, vol. 35, pp. 1383-1386, 2019.

[6] M. N. Wahab, A. R. Daud, and M. J. Ghazali, "Preparation and characterization of stir cast aluminum nitride reinforced aluminum metal matrix composites," International Journal of Mechanical and Materials Engineering, vol. 4, no. 2, pp. 115-117, 2009.

[7] G. Narasaraju and D. L. Raju, "Characterization of hybrid rice husk and fly ash-reinforced aluminium alloy (AlSi10Mg) composites," Materials Today: Proceedings, vol. 2, no. 4-5, pp. 3056-3064, 2015.

[8] B. A. Kumar and N. Murugan, "Metallurgical and mechanical characterization of stir cast AA6061-T6-AlNp composite," Materials \& Design, vol. 40, pp. 52-58, 2012.

[9] O. S. I. Fayomi, O. O. Joseph, I. G. Akande, C. K. Ohiri, K. O. Enechi, and N. E. Udoye, "Effect of CCBP doping on the multifunctional Al-0.5 Mg-15CCBP superalloy using liquid metallurgy process for advanced application," Journal of Alloys and Compounds, vol. 783, pp. 246-255, 2019.

[10] M. Abdulwahab, I. A. Madugu, S. A. Yaro, S. B. Hassan, and A. P. I. Popoola, "Effects of multiple-step thermal ageing treatment on the hardness characteristics of A356.0-type Al-SiMg alloy," Materials \& Design, vol. 32, no. 3, pp. 1159-1166, 2011.

[11] O. S. I. Fayomi, A. P. I. Popoola, and N. E. Udoye, "Effect of alloying element on the integrity and functionality of aluminium-based alloy," Aluminium Alloys: Recent Trends in Processing, Characterization, Mechanical Behaviour and Applications (Chapter 13), pp. 243-260, 2017.

[12] N. Prasad, Development \& Characterization of Metal Matrix Composite Using Red Mud an Industrial Waste for Wear Resistant Applications, Thesis National Institute of Technology, Rourkela, India, 2006.

[13] U. Rattanasak, P. Chindaprasirt, and P. Suwanvitaya, "Development of high volume rice husk ash alumino silicate composites," International Journal of Minerals, Metallurgy, and Materials, vol. 17, no. 5, pp. 654-659, 2010.

[14] V. K. Sharma, R. C. Singh, and R. Chaudhary, "Effect of flyash particles with aluminium melt on the wear of aluminium metal matrix composites," International Journal Engineering Science and Technology, vol. 30, pp. 10-15, 2018.

[15] N. E. Udoye, O. S. I. Fayomi, and A. O. Inegbenebor, "The study on improvement of aluminium alloy for engineering application: a review," International Journal of Mechanical Engineering and Technology, vol. 10, no. 3, pp. 541-545, 2019.

[16] J.-h. Peng, X.-l. Tang, J.-t. He, and D.-y. Xu, "Effect of heat treatment on microstructure and tensile properties of A356 alloys," Transactions of Nonferrous Metals Society of China, vol. 21, no. 9, pp. 1950-1956, 2011.

[17] R. A. Kumar, A. Devaraju, and S. Arunkumar, "Experimental investigation on mechanical behaviour and wear parameters of tic and graphite reinforced aluminium hybrid composites," Materials Today: Proceedings, vol. 5, no. 6, pp. 14244-14251, 2018.

[18] A. K. Senapati, S. K. Sahoo, S. Singh, S. Sah, P. R. Padhi, and N. Satapathy, "A comparative investigation on physical and mechanical properties of MMC reinforced with waste materials," International Journal of Engineering and Advanced Technology, vol. 5, no. 4, pp. 161-168, 2016.

[19] A. P. S. V. R. Subrahmanyam, G. Naresh, and V. Venkatesu, "Microstructure and mechanical properties of rice husk ash reinforced aluminium alloy (A356.2) metal matrix composite," IOSR Journal of Engineering (IOSRJEN), vol. 8, no. 6, pp. 36-42, 2018.

[20] H. Haque, R. Ahmed, M. Khan, and S. Shahriar, "Fabrication, reinforcement and characterization of metal matrix composites (MMCs) using rice husk ash and aluminium alloy (A356.2)," International Journal of Scientific and Engineering Research, vol. 7, no. 3, pp. 2229-5518, 2016.

[21] A. M. Valyakala, J. Dileeplal, and B. Paul, "Root cause analysis for the failure of a forced draft fan in a petrochemical industry," International Journal of Engineering Research and Development, vol. 6, no. 5, pp. 84-90, 2013.

[22] T. N. Kushwaha, "Fatigue failure analysis of a cooling fan blade: a case study," International $O$ and M Conference, vol. 6, pp. 717-726, 2017.

[23] H. Soares, T. Zucarelli, M. Vieira, M. Freitas, and L. Reis, "Experimental characterization of the mechanical properties of railway wheels manufactured using class B material," Procedia Structural Integrity, vol. 1, pp. 265-272, 2016.

[24] S. D. Saravanan and M. S. Kumar, "Effect of mechanical properties on rice husk ash reinforced aluminum alloy (AlSi10Mg) matrix composites," Procedia Engineering, vol. 64, pp. 1505-1513, 2013.

[25] D. Siddharth and J. B. Rao, "Synthesis and characterization of RHA (rice husk ash) particulates reinforced A7075 composites," International Journal of Advances in Mechanical and Civil Engineering, vol. 4, no. 3, pp. 105-110, 2017.

[26] M. A. Maleque, A. A. Adebisi, and N. Izzati, "Analysis of fracture mechanism for Al-Mg/SiCp composite materials," Materials Science and Engineering, vol. 184, no. 1, 2017.

[27] S. Ozden, R. Ekici, and F. Nair, "Investigation of impact behaviour of aluminium based $\mathrm{SiC}$ particle reinforced metalmatrix composites," Composites Part A: Applied Science and Manufacturing, vol. 38, no. 2, pp. 484-494, 2007.

[28] S. Chandrasekhar, P. N. Pramada, and J. Majeed, "Effect of calcination temperature and heating rate on the optical properties and reactivity of rice husk ash," Journal of Materials Science, vol. 41, no. 23, pp. 7926-7933, 2006.

[29] A. Apasi, D. S. Yawas, S. Abdulkareem, and M. Y. Kolawole, "Improving mechanical properties of aluminium alloy through addition of coconut shell-ash," Journal of Science and Technology, vol. 36, no. 3, pp. 34-43, 2016.

[30] V. Gupta and S. Takhi, "Effects of rice husk ash particulates on the mechanical and tribological properties of the aluminum metal composite reinforced with aluminum oxide," International Journal for Scientific Research and Development, vol. 3, no. 3, 2015. 